\title{
GUIDELINES FOR CONDUCTING \\ EDUCATION ABROAD DURING COVID-19
}

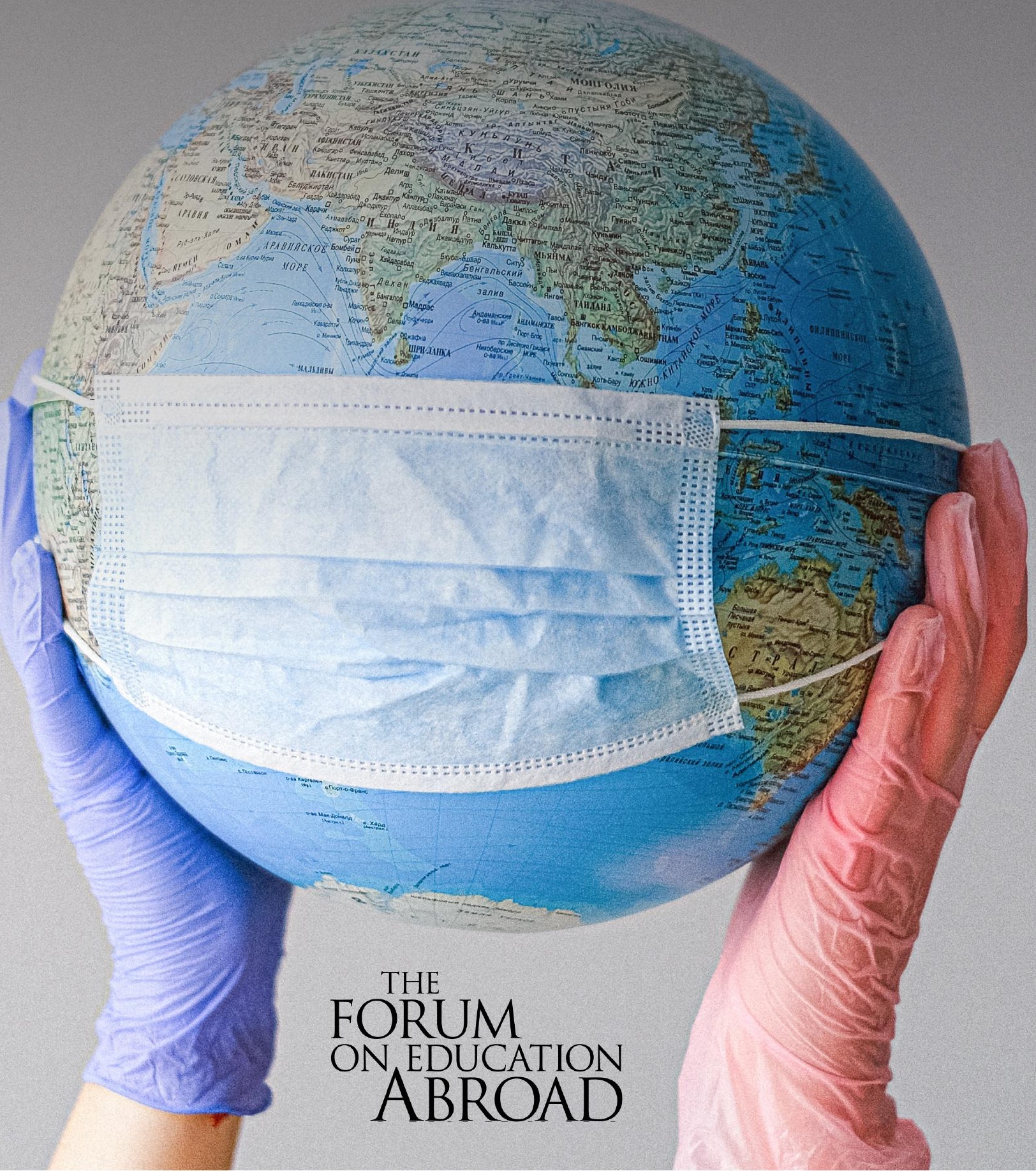




\section{ACKNOWLEDGEMENTS}

The Forum thanks the following individuals for their contribution to the preparation of this Guide:

Andrea Bordeau, Vanderbilt University

Gian Franco Borio, attorney at law in Florence, Italy, legal counsel to AACUPI and EUASA

Enda Carroll, University College Dublin

Elena Corbett, AMIDEAST

Amelia Dietrich, The Forum on Education

Abroad

Jennifer Ewald, Fairfield University

Andrew Faas, Institute for Study Abroad

(IFSA)/London

Elizabeth Frohlich, The Forum on Education

Abroad

Maureen Gordon, Arcadia University, The College of Global Studies

Steve Hopkins, Cultural Insurance Services International (CISI)
Bill Hoye, IES Abroad

Leanne Johnson, University of Maryland

Stephanie Kelly, CCID

John Lucas, ISEP

Natalie A. Mello, The Forum on Education Abroad

Emily Merson, Global Experiences

Alexandra Mitchell, CEA Study Abroad

Patrick Morgan, University of Michigan

Amir Reza, Babson College

David Sadoff, University of Pennsy/vania

Joe Storch, SUNY System

John Sunnygard, University of Western Kentucky

Melissa Torres, The Forum on Education Abroad

Dawn Wood, Kirkwood Community College

(c) 2020 The Forum on Education Abroad.

ISBN: 978-1-952376-07-8

doi.org/10.36366/G.978-1-952376-07-8

The Forum on Education Abroad

PO Box 1773

Carlisle, PA, USA 17013

The Forum on Education Abroad is hosted by Dickinson College.

www.forumea.org 
INTRODUCTION

The world is a different place now than it was before the COVID-19 pandemic. Given what has happened in our field and in the world, it is pertinent to err on the side of caution in order to protect our students, our institutions and organizations, our communities, our partners, and ourselves. This document is written to help education abroad professionals think through the many steps to make education abroad feasible during and after the COVID-19 pandemic and to mitigate risk associated with education abroad and student mobility during an unprecedented period in our field's history. It is intended for use within organizations and by partners from different organizations to help guide their development of a plan for returning to and/or scaling up education abroad operations in the wake of the COVID-19 pandemic.

We begin this guide by emphasizing the importance of a conservative and holistic approach to developing policies, procedures, plans, and back-up plans for education abroad before once again offering international mobility opportunities to students on a large scale. While these guidelines should not be considered exhaustive, and there is no one-size-fits-all strategy for the different types and kinds of organizations and institutions that are involved in education abroad, they can be incorporated into existing plans and protocols being developed at an institution or organization.

In addition to the specific advice that follows, we encourage readers and users of these guidelines to be informed by the following considerations with respect to reopening education abroad:

- Convincing education abroad stakeholders, such as institutional leadership, students, and their families, to return to education abroad will require strong policies that demonstrate that your department or organization is putting health and safety first, proactively planning, and ever mindful of ongoing challenges.

- Take an institution-wide or enterprise-level approach to discussions and decisions, especially related to risk management, legal considerations, insurance, and funding for education abroad. The
COVID-19 pandemic has focused attention on education abroad operations in new ways. Take advantage of this opportunity to engage outside stakeholders more deeply and empower them to be champions and advocates of education abroad.

- Entities in different locations and comprising different constituencies will approach the current challenges in various ways and with solutions that fit their unique situation. Understanding that sometimes decisions may not be at the discretion of individual organizations, campuses, programs, or offices with whom you are collaborating, remember that we are all facing extraordinary challenges and keep the long-term goals in mind when communicating with partners and stakeholders.

- Due to ongoing shifts in the geopolitical environment during and due to COVID-19 and response to the pandemic, planning for a return to large-scale student mobility should also include considerations for how these shifts could impact students or programs.

- The changes made to education abroad in response to COVID-19 are also likely to change the student experience on-site, perhaps drastically. Intentional co-creation between partners of programs that offer students rich, if alternative, experiences, is more important now than ever. So, too, are communication and expectation management between partners, with onsite staff, and with students.

This guide is being written in June-August 2020 based on the best available information at the time. The Forum on Education Abroad will continue to monitor the COVID-19 situation as it evolves and review this document regularly. Updates or addenda may be added as needed.

For general guidance on what makes quality education abroad programming possible, use the Standards of Good Practice for Education Abroad as a reference. 


\section{GUIDING PRINCIPLES}

\section{1* MISSION AND GOALS}

a. Institutions and organizations must remember why and how education abroad aligns with their overall mission and goals and keep this in mind when making decisions during moments of crisis or uncertainty.

1. Education abroad students and staff may not be the only individuals on a campus or in an organization who are being impacted by the evolving COVID-19 situation and related decisions made by their own or other organizations.

2. Education abroad professionals have specialized skills and networks that may be of use to address challenges in addition to those posed to education abroad.

b. Institutions and organizations should consider the impact of decisions related to education abroad on their institution/ organization's larger global audience and their long-term internationalization strategy.

c. Within organizations, when an international challenge has been identified, education abroad leaders should be consulted by organizational leadership immediately, before any actions are taken.

d. Academic continuity for education abroad programs must be a priority for organizations and should be an essential component of institutional internationalization plans.

1. Education abroad professionals should gain support for academic continuity and risk management planning from stakeholders at the highest levels, e.g., Presidents and Chancellors.

e. Use educational objectives of the program to guide determination of what constitutes "essential travel." Minimize non-essential travel within programs and for other international activities to reduce the risk of exposure of participants and others.

\subsection{COLLABORATION AND TRANSPARENCY BETWEEN PARTNERS}

a. Partners should agree in advance on the potentially applicable laws that should inform policies and planning during/after COVID-19. For more guidance on specific areas of law to consider, see Appendix A: Areas of Law that Could be Implicated.

b. Establish and/or reaffirm business relationships where all stakeholders in a partnership follow mutually agreed upon policies and procedures and comply with applicable laws to the extent possible in order to create a presumption of good faith.

c. Ensure that each partner is committed to and practices open and honest communication, particularly in the midst of a crisis.

1. Establish communication protocols between partners, including forms and timelines, response times, and reporting procedures for both routine and emergency communications.

d. Commit to collaborative, transparent decision-making. Discussing options to arrive at mutually acceptable solutions is critical.

e. Directly address the balance or imbalance of power between universities and providers.

f. Discuss the risk tolerance of each party in the COVID-19 context, acknowledging that in some cases the need to make changes may be time sensitive.

g. Acknowledge the limitations of collaboration and establish reasonable expectations.

h. Review all partner contracts and protocols in light of the pandemic.

1. Were there any breakdowns in protocols, procedures, or communications during the initial phase of the COVID-19 pandemic? How can these be avoided in the future?

${ }^{*}$ For ease of reference, sections are numbered to match the corresponding clauses of the Standards of Good Practice 
2. Does anything in the existing contracts need to be reconsidered? Are roles and responsibilities clear?

3. Which decisions does each party need to make in a crisis?

4. Which party is responsible for communicating with participants, insurance providers, and service/care providers?

5. Clearly outline expectations regarding insurance coverage minimums. Be reasonable in these expectations, taking into account differences in currencies and insurance norms and availability in other countries. Retain flexible amounts in terms to the extent possible.

i. In establishing or reviewing contractual agreements between partners, prioritize and commit to:

1. Equitable assumption of liability

2. Fair and equitable refund policies, taking into consideration:

- cost of program;

- model by which costs are covered (i.e., are students paying home institution tuition and/or fees for a less expensive study abroad program with a provider, are scholarships covering students, etc.?);

- location of program (e.g..., is it in a Global South/Majority World country, does it support some sector of a disadvantaged economy, is it in a place subjected to colonialism, racism, debt, etc.?);
- differences among providers (e.g., size), differences between provider and university resources; what did the provider provide both in an emergency and in terms of finishing the program?);

- need to reallocate funds to provide different services in the event of a crisis or emergency; and

- need for emergency funding to support financially vulnerable students.

3. Clear distribution of responsibilities between partners regarding communicating public health messages, educating students about personal responsibility related to using face coverings, etc., sanitation guidelines, case or incident management, disciplinary actions and consequences for students who don't comply, etc.

4. Responsibility for additional needs and costs for facilities and equipment in the context of COVID-19.

5. Clear decision-making protocols for crisis response.

6. Clear terms for terminating a contract

7. Clearly articulated consequences each party will face for breach of contract.

8. Identify signatories and decisionmakers with institutional authority to sign, and whether these might differ in the context of a crisis. Review and acknowledge legally binding aspects of contracts at time of signing.

j. Ensure the sharing of accurate information on local rules, safety protocols, and confidentiality requirements on a continual basis and in a timely manner as they are updated.

k. Executing response plans, e.g., academic continuity or evacuation plans, etc., requires cooperation, collaboration, and flexibility. Partners should work together so that the needs of both are met. 
I. Local regulations can change quickly, affecting the requirements and mandates for local organizations and institutions. All partners should be flexible when the local or national legal environment affecting a partner organization changes.

m. Plans must take into account the availability of necessary resources at all organizations involved in the partnership (including, e.g., relevant faculty, administrators, and advisors).

n. Plans should consider the potential financial impact on organizations and stakeholders.

o. Plans should be feasible for all partners involved. Contingency plans should take into consideration the realities of resources, travel, technological capabilities, the availability of refunds, and changing circumstances.

Note: The Guidelines for Good Business

Partnerships (2019) provide additional guidance for establishing and maintaining strong relationships with partners who help you deliver education abroad programming to your students.

\subsection{ETHICS}

a. Determine specific financial and safety risk tolerance levels and use that information to inform planning, decision-making, and collaboration with partners. Be transparent and forthcoming with partners.

Ask, for example:

1. Does your organization have the funds available to:

- cover the costs associated with requiring students to quarantine separately

- evacuate/repatriate students quickly in the event of another major outbreak

- pay on-site staff and service providers even if a program is canceled

- offer a partial refund to students if programs are cancelled or switch to virtual programming

2. If you are working with a partner to deliver a program, do they have the funds available to cover the costs in (a) above?

3. If your partner cannot offer certain financial support, is your organization willing to assume the responsibility for costs as in (a) above anyway?

4. Have you discussed these limitations with stakeholders and partners before the program begins?

b. Consider not only the risk of COVID-19 to a program's own students and personnel, but also whether bringing international participants into a local community poses an increased risk of infection or potentially puts undue strain on resources in the community where the program takes place.

c. Consider the economic and social impact that canceling a program can have on the local community where the program was planned. Often in host communities, relationships and infrastructure are built to accommodate visiting students and other guests. 


\subsection{EQUITY, DIVERSITY, AND INCLUSION}

a. Treat students, faculty, and staff equitably when requiring testing, temperature and symptom checking, quarantining, accommodations, and assessment of academic work.

b. Academic continuity plans shall be equitable across academic disciplines, levels, and program type.

c. Academic continuity and communication shall be considered for and applied equitably to all students impacted by a program closure or disruption, including matriculated, international, and visiting students.

d. Plans should include the identification of emergency funds available to assist lessresourced students whose ability to study remotely or return home safely is impacted by the pandemic.

1. Institutional partners should agree in advance who will provide what funds and on what basis and schedule they will be disbursed.

e. Identify mitigating circumstances that might need to be considered regarding less-resourced students, including, e.g., access to other housing if a program is cancelled, availability of communication technology and high-speed internet for synchronous online coursework, etc.

f. Determine how students will be accommodated academically if they arrive from a country for which quarantine is mandated.

1. If students in the same program are from a variety of countries, plan accommodations so that no student(s) are at a disadvantage relative to classmates who are not required to quarantine.

g. When working with multiple partners, make a plan to avoid possible inequitable outcomes for participants in programs with different partners. Plan should include policies for accommodating students whose institutions require them to depart prior to the completion of the academic program.

\section{ADMINISTRATIVE FRAMEWORK}

\subsection{POLICIES, PROCEDURES, AND GUIDELINES}

a. Program Design and Planning:

1. Develop a plan for delivering academic content at a variety of stages of course or program completion, i.e., what will you do if students must be repatriated after $25 \%, 50 \%$, or $75 \%$ of the program?

2. In partnerships, ensure understanding of all partners' criteria for moving a program online.

3. Make a plan for supplementing program components only accessible in-country.

4. Consider how to design timelines strategically to accommodate the partial or full reopening of education abroad at an institution on short notice or at a different point in the academic calendar than usual.

b. Personnel Matters:

1. Programs and program staff have a right to be informed and should seek to implement all required actions to meet workplace conformity concerning COVID-19 protective measures based on standards and guidelines mandated by the location where the program is operating.

2. Require faculty and staff to go through training and demonstrate understanding of program insurance policies. Do they know: who to call, how to access insurance, what payments they need to be prepared to cover up-front, etc.? 


\section{c. Student Matters:}

1. Program policies must clearly state whether or not academic continuity will be available should students decide on their own to leave a program before the official end date, and under what circumstances.

2. Refund policies must clearly state conditions and terms affecting refunds. Are tuition, housing, or other fees refundable in part or whole and what circumstances affect refund amounts and/or availability?

- Policies should also indicate whether refunds could be available if the academic content is delivered in a different modality than foreseen and what, if any, refund may apply.

3. Establish expectations and consequences concerning personal travel by participants during free time or before or after the program start and end dates.

d. Health, Safety, and Risk Mitigation:

1. Set clear and consistent safety protocols for all personnel and participants.

2. Establish policies and protocols to mitigate risk to program participants and personnel as well as local communities.

3. Identify organizational stakeholders to involve in decision-making during policy and procedure development. Build partnerships with other units or offices where helpful.

4. Seek various sources of information and resources to inform policies and procedures.

- Look to different sources of expertise on the local level: health boards, legislation, school boards or education ministries

- Look to different sources of expertise on the national level: national health organizations and travel guidance, e.g., Centers for Disease Control (CDC) or
Know Before You Go: Guidance for travel in Great Britain and Northern Ireland; insurance providers; legislation; in-country study abroad associations (e.g.: APUNE, APUAF, ASAPI)

- Look to different sources of expertise on the regional level, e.g., European Union (EU)'s Centre for Disease Prevention and Control, EUASA, AEI, APIAE, AAU, CBIE, UDUAL, FAUBAI, etc.)

- Look to different sources of expertise internationally: WHO, London School of Hygiene and Tropical Medicine, experts on your campuses (e.g., epidemiologists and public health experts).

5. Determine which guidelines will be the ones your organization trusts and follows. Revisit and reconsider previously-held policies, ideas, or "tripwires" in favor of reasonable consideration of prevailing and reasonably predictable conditions across locations where decisions may have impact.

6. Responsible parties have a duty to know what the local practices and laws are regarding quarantine, selfisolation, social/physical distancing, use of personal protective equipment, etc., upon arrival to the program location, upon return to home country, and in any country through which participants must travel to reach their destinations.

- Assist students in understanding and complying with these requirements. 
7. Ensure that your policies and procedures take into account the answers to the following questions:

- How does guidance on the home campus differ from guidance onsite?

- Is quarantine or self-isolation required upon arrival to the program location(s)? How is this defined in different locations? Are quarantine accommodations in place for program participants, should they be prepared to selfquarantine, and what is the role of local program staff in monitoring students' quarantine?

- Are there COVID-19 virus or antibody testing requirements in the program location(s)?

- What are the physical distancing requirements in program location(s)?

- Are there requirements to wear masks or other personal protective equipment in the program location(s)? What are they?

- Are there travel or mobility restrictions in place within and between program locations?

- What do you expect of your participants and partners in terms of complying with these regulations and policies? What do they expect of you?

- Can you offer a program of quality with a 14-day delay in the activities on the ground due to quarantine requirements?

- Is quarantine, self-isolation, or testing required upon return to the home country? What does this entail?

8. Compliance with all applicable laws and guidelines (e.g., local to program site and to program sponsor location) is the best defense for limiting potential tort or other non-contractbased liability if someone involved with the program were to get sick.
9. Conduct a thorough review of all sites and programs being considered, even if these are locations or programs that have been previously approved.

10. Always have contingency plans in place that consider the capacity on the local level to support participants as the pandemic evolves or in the event that the location in question has a major outbreak.

11. Provide clear documentation, and follow relevant policies and procedures for tracking, responding to, and reporting critical incidents.

12. Develop agreements around informed consent and waivers that:

- Require participants to acknowledge that they understand risks;

- Consent to following guidelines regarding testing, temperature and symptom checking, masks, quarantine/self-isolation, etc.;

- Require participants to agree that they won't hold the organization legally or financially responsible if they become ill as a result of their own choices and behaviors; and

- Convey the importance of disclosing relevant medical information, disability status, accommodation, or other specific needs.

13. Recognize that any liability waivers may have little or no validity in the host country.

14. Communicate clear expectations for conduct and consequences of behaviors regarding:

- Testing, masks, social/physical distancing, quarantine;

- Required reporting of contact with infected individuals;

- Disciplinary sanctions for noncompliance; and

- Appeals processes. 
15. Decide whether or not your organization will allow individuals to waive your program's selected insurance.

Note: When a group of people need to be treated or evacuated all at once, as in the case of a pandemic, but also in situations like bus accidents, etc., managing different policies, companies, and coverages is detrimental to the efficacy of emergency response and can leave some individuals at greater risk than others.

16. Establish clear policies regarding privacy issues that conform with applicable laws (GDPR, FERPA, cell phone data to do contract tracing, etc.)

17. Establish a policy for what happens if a participant decides to remain incountry after a program recommends leaving.

- Consider using waivers or a notice of change to standard of care to notify students of issues they may encounter abroad after a program has been suspended.

- Include language about insurance coverage in any waiver or notice document.

- Don't cancel any prepaid insurance plans, but make sure students understand that the plan will be or could be cancelled by the insurance provider.

- Inform students if the option to extend insurance coverage if they remain in-country past the original policy dates may not be available.

- Require students to acknowledge understanding by signing notice/ release.

\subsection{FINANCIAL AND HUMAN RESOURCES}

a. Know and implement workplace safety measures for staff and faculty.

b. Ensure provisions and reasonable accommodations for participants and personnel with higher than average risk.

c. Provide training for faculty and staff specific to program needs and local laws and guidelines.

d. Offer an employee assistance program to support faculty and staff wellbeing.

e. Be aware of employment law considerations that apply, including:

1. Liability can derive from violation of national law (home or host country) or possibly from violation of international standards.

2. Compliance with applicable laws and standards is tantamount.

3. Standards and practices concomitant with centralized, national responses to COVID-19 are and should be the norm.

f. Engage other stakeholders in a conversation about education abroad insurance as a part of a larger enterpriselevel/institution-wide approach to insurance and risk management.

Remember: Education abroad participants may not be the only individuals on a campus or in an organization who will require insurance. This should be a part of, not separate from, a more comprehensive approach.

\section{Discuss the following questions:}

- Where does the funding come from to pay for insurance policies?

- Where does the money come from to cover expenses that insurance won't cover?

- Who makes the decision to change policies?

- When is a good time to change policies? Is now a good time to change policies? 
- Who is involved in the RFP and policy negotiation process?

- Who needs to be insured?

- Can we consolidate policies across a consortium, district, or state system? (Note: The more people you have in the pool, the lower the premium.)

g. Revisit all insurance contracts and plans in light of the COVID-19 pandemic, including:

For individuals: Medical, Trip Cancellation/ Interruption, Security Evacuation

For entities: Business Interruption, Property Casualty Insurance

- The insurance industry is changing products in response to challenges that arose with COVID-19. Don't assume you're getting the same policy you had before.

- As elsewhere, insurance companies and emergency service providers have faced layoffs and budget cuts. Don't assume you can rely on the same level of expertise and service you had before.

- Ensure that all losses are documented and that any insurance claims are timely filed.

See Appendix B: Know Your Policy for a list of more specific questions to ask when vetting new insurance policies or reviewing existing policies.

h. After (g.) above, revisit and vet your policies and providers regularly.

- Establish a set schedule for review.

- In addition to regularly scheduled reviews, revisit your policies after any major event (e.g., major evacuation, spike in participant infections, etc.) to review the policy to ensure that it is still adequate for your purposes. i. Know what local and international laws are regarding medical evacuation and/ or repatriation of remains in a COVID environment.

Note: New restrictions apply in many locations.

1. Be prepared to work within these parameters as needed.

j. Have a clear policy about self-insurance and know how you will pay for the things you can't buy an insurance policy to cover. Insurance covers some risks, but it will never cover all possible risks. To be prepared for those risks which are not covered by insurance, ask:

- What extra funds does your organization have available to cover the costs for outstanding circumstances outside of the structured risk your insurance policies cover?

- Where do these funds come from or could they come from? E.g., general fund, office budget, study abroad fees, application fees, building "cushion" into program budgets.

- Align this with the overall institutional philosophy around risk tolerance and task reserves.

- What can these funds be used for? What are the criteria for disbursement? Who decides? Establish all of these policies in advance.

- How have students been prepared to have extra funds available for outstanding circumstances they may encounter with which your organization won't be able to help?

NOTE: Remember, certain policies won't pay out until the end of the term of the policy, so you may need cash available in the short-term, even if you can count on it being paid back later. 


\section{STUDENT LEARNING AND DEVELOPMENT}

\subsection{BEFORE PROGRAM}

a. Each institution or organization participating in education abroad must have a plan for continuing the academic portion of its programs, where feasible, in the event that the on-site portion of the program is cancelled, delayed, or otherwise impacted. When preparing this plan, consider:

1. What regulatory factors (local, federal, global) might affect academic continuity plans?

2. How might students be impacted by geopolitical power shifts?

b. Provide students with a clear description of the various options for program delivery in advance of a financial commitment by the student.

1. Include a detailed description of blended or online learning options and technologies that may be employed.

c. Seek to obtain information about the academic continuity plans of your counterparts when students are participating in programs run through partnerships or sponsored by organizations other than your own.

d. Make academic continuity plans available to students during the advising process or prior to any financial commitment from students.

e. Consider whether internal resources are available to substitute the delivery of academic content, should a partner organization be unable to complete the academic program (e.g. IT, proctoring, capacity in existing courses at the home institution, human capital, infrastructure, advising). f. Clearly communicate with students the academic continuity options available for various programs and partner organizations.

1. Home institutions should consider developing a plan to address possible inequitable outcomes for students studying at host institutions or programs with varying levels of resources.

g. Program leaders and faculty must be prepared to switch modalities.

1. Consider preparing hybrid models simultaneously with face-to-face models so as to be prepared for a sudden change.

2. To the extent possible, organizations should provide support to faculty such as technology, training, or reduced research requirements.

h. Education abroad administrators must be ready with plans to assist faculty through transitions in the event they must be repatriated along with their students.

i. Educate participants and personnel to adhere to a common set of policies and behaviors to mitigate risk to their health and wellbeing and others'.

1. Rather than "doing training to students," engage them as partners with a shared goal.

2. Recognize the agency of participants.

3. Consider partnering with families to support participants' education and continued compliance with community policies.

j. Use informed consent along with waivers to document what is expected of all participants.

k. Reframe self-disclosure of pre-existing conditions to focus on the reasonable capacity of the program or location to ensure healthcare and student wellbeing. 
I. Endeavor to be forthright and transparent regarding organizational policies and procedures and evolving situations related to the COVID-19 pandemic and other concerns at all times.

m. Collect, monitor for modification, and communicate to all stakeholders what local, on-site institutions and communities are requiring or not requiring concerning obligation for class attendance, physical distancing, access to local campus resources, etc. so that participants and stakeholders can make informed decisions about comfort level participating in specific programs abroad.

n. Set clear expectations for participants. Remind them that just because they have insurance doesn't mean that they don't need to manage their own risk in other ways.

o. Help participants understand what is covered and what isn't under any insurance policy supplied by the program/ sponsoring organization.

1. Try using an online course or quiz that requires students to acknowledge understanding.

2. Make participants aware of the risks that aren't covered by their policy and any associated out-of-pocket costs those could incur.

3. Inform participants whether their insurance policy can be extended preor post-program dates and provide information about how to request that extension, if applicable.

4. Make policies and emergency contact information available and easily accessible to participants.

5. Ensure that participants take releases and disclosures seriously, e.g., HIPAA, identifying a reliable emergency contact. Make sure they understand what the purposes of these documents are.

6. If multiple policies cover participants, be prepared to explain to participants why they are needed and how they differ.

\subsection{DURING PROGRAM}

a. Monitor evolving COVID-19 pandemic and geopolitical situations constantly.

b. Communicate regularly with participants and other stakeholders (e.g. home institutions, families) about evolving situations on-site.

c. Reinforce health and safety protocols and community standards as covered in the pre-program period by utilizing posters in common areas, periodic reminders via email correspondence, review of policies and procedures in class or during a midprogram meeting or check-in, etc.

d. Ensure that on-site staff and participants are aware of the evolving situation in their home country so that participants can make an informed decision about whether they can or should return home during or post-program.

e. Monitor participants and staff for symptoms of COVID-19 and begin testing and isolation protocols as needed.

f. Track or ask participants and personnel to track where and with whom they are interacting to facilitate contract tracing in the event of a suspected or confirmed infection.

g. Employ a case management plan with stated milestones and decisions dates in case of

1. Participant illness

2. Fear of illness (heightened anxiety)

3. Known or likely contact with an infected individual

4. Violation of policies

5. A "second wave"

6. Spike in illnesses locally

7. Limit visits from individuals nonessential to program delivery, such as friends and family of students or program personnel.

8. Consider, establish, and communicate a policy or position on participant travel outside of the program destination. 
h. Be prepared to shift modalities quickly if needed. This can greatly impact the success of academic continuity planning.

1. Ensure in advance that course content can be delivered remotely if circumstances demand.

i. Employ a student-centered approach for using flexible timelines, deadlines and grading/evaluation for course completion or academic requirements to mitigate disadvantage onset by variation of learning modality should changes be made mid-program.

1. If operating programs in multiple locations, consider organizing regional calls or virtual meetings with staff and/or partners in different locations to coordinate academic continuity plans and other decisions.

2. Offer student counseling services to support mental and physical health and well-being.

\subsection{AFTER PROGRAM}

a. Encourage students to report any symptoms or positive COVID tests that begin within 15 days of the end of the program to program staff as well as to their home school (if they've already returned to campus) or local healthcare provider (if they are at home/not on campus).

b. Ask participants to reflect on how COVID-19 impacted their education abroad experience.

1. Be prepared to share feedback with partners and future students to strengthen future program protocols and experiences.

c. If program is cancelled or disrupted suddenly:

1. Provide participants with proper documentation of courses and any mid-program changes to coursework or delayed testing needed to facilitate awarding/recognition of credits earned abroad. Assist students where possible with this process. Be flexible given evolving situations.

2. Consider offering debriefing opportunities or support for participants negatively impacted by this experience.

d. Connect students to other virtual opportunities or international mobility options in the future. 


\section{APPENDIX A: AREAS OF LAW THAT COULD BE IMPLICATED}

\section{National or regional laws, e.g.:}

- Workplace safety standards

- Use of government funding or representation about its use (if audited)

- Financial aid and work-study regulations

Tort negligence (e.g., if someone becomes ill from coronavirus as proximate cause of breach of duty owed, and illness is reasonably foreseeable)

- To avoid such liability, must act as reasonable person would under the circumstances by, at a minimum, complying with applicable laws and guidelines; to be distinguished from intentional or statutory torts

- Legal standards might be based on CDC, OSHA, State Dept. Travel Advisories, host country agencies, WHO, etc.

- Defenses could include contributory/ comparative negligence, assumption of risk, or failure to prove causation (difficult to pinpoint how and when a person has contracted the virus)

- Types of conduct that, if neglected, could give rise to tort negligence:

- Health and hygiene arrangements, e.g.:

- Provide a nurse's station

- Ensure there is a safe place where participants can quarantine if they get infected

- Screen upon entry to school premises

- Availability of hand wash stations on campus

- Regularly sanitize frequently touched surfaces

- Remind students/others to stay home if they have symptoms

- Require face masks be worn (and provide, as necessary)

- Regularly test and monitor

- Ensure adequate COVID-related signage on campus, in housing, or in program facilities

- Provide contract tracing

- Ensure adequate accommodations for high-risk individuals

- Require self-quarantining if returning to location after travel

- Ensure proper health and hygiene arrangements are available during all co-curricular or experiential activities that are included as part of the program.

- Social/physical distancing, e.g.:

- Student residences

- Campus dining

- Classroom configuration: Smaller class sizes and reconfigured spaces, staggered class schedules

- One-way stairwells

- No assemblies, athletics, limiting face-to-face meetings, encouraging videoconferencing

- Availability of counseling services

- Student social and emotional support (pastoral care)

- Employee Assistance Program

- Timing regarding suspension of program

\section{Breach of contract, e.g.:}

- Between home school and host school

- Between home or host school and service provider

- Between school or service provider and third parties (e.g., vendors)

- Between school or service provider and faculty (based on local labor laws)

- Between school or service provider and parents (e.g., for reimbursement of fees, emergency evacuation costs, diminished value of education if in remote learning mode; failure to accommodate students on campus or in classrooms if return early from overseas) 


\section{Discrimination claims, e.g.:}

- Who gets tested or temperature checked and how frequently?

- Who is required to quarantine and under what conditions?

- Subjecting individuals to inequitable standards/treatment re: reimbursement if program suspended, if offer preferred travel opportunities home for some, or if differential treatment of those who violate program rules

- Ensuring safety policies do not mistreat persons who fall within a protected category and that disability accommodations related to any online work are adequate and in compliance with applicable law

\section{Privacy issues, e.g.:}

- Requesting health information

- Relying on cell phone data to do contract tracing

- Mishandling of privacy-protected medical info re: GDPR (Europe), HIPAA (U.S.)

\section{Due process rights infringement, e.g.:}

- Requiring testing, temperature checks, facemasks, etc.

- Forced self-quarantine or isolation

- Disciplining for failure to comply with restrictions

\section{Local reporting requirements, e.g.:}

- Opening or closing program

- Number of infections

- Number of deaths

\section{Visa/entry/border closing concerns}




\section{APPENDIX B: KNOW YOUR POLICY}

\section{When reviewing existing or prospective insurance policies for education abroad programming, ask these questions:}

Who is covered? What is covered? What exclusions apply to the policy/ies?

\section{For individual coverage:}

- Can faculty, staff, students all be on the same policy? (If possible, this is preferable.)

- Is there any exclusion from coverage on the basis of age?

- Do we have a dependent coverage policy for anyone who might accompany program participants?

- What are the policy start and end dates?

- Is there an exclusion for viral pandemic or epidemic?

- Medical insurance covers individuals contracting a disease,

- But what about individuals at-risk, but who haven't contracted it yet?

- Does medical insurance cover the costs of testing? For whom? Only individuals with symptoms? Only if exposed? Or for any reason? Is testing covered just once or multiple times?

- Is there an exclusion for those who travel against a warning to a State Department Level 4 travel advisory or CDC Level 3 location?

- What happens if the warning changes while insured are in-country?

- Does insurance kick back in if the advisory goes back down to lower level at a later date?

- What are the deductibles and co-pays? Can the organization or an individual have the cash available to pay that amount if needed?

- Does the plan make direct payment to foreign providers? If not, how will you seek reimbursement later? Does the individual or organization have cash on hand to pay the costs at time of care?
- Does the policy offer coverage at home for participants who return home prior to policy end date?

- Does the policy offer coverage outside of one's registered destination(s)?

- Other exclusions and coverages to confirm:

- Drug and alcohol exclusions

- Mental health care coverage

- Exclusions when participating in athletics or organized sports

- Exclusions when participating in inherently dangerous activities, e.g., scuba, mountain climbing, horseback riding, driving a motor vehicle, 2- and 3 -wheel vehicles, off-roading, etc.

\section{For business coverage:}

- Be familiar with the organization-wide umbrella policy if one exists.

- Hold regular meetings with the organization-level person (legal counsel, risk manager, insurance specialist) who manages that policy.

- Is there a viral pandemic or epidemic exclusion?

- Does it cover canceling or interrupting a program for any reason?

- What's the upper limit on coverage under the policy?

- What are the deductibles? Does the organization have cash reserves to cover this if needed?

- Does the policy include coverage for property damage and loss of business?

- Does the policy include liability coverage? How much?

- How does one make claims, what applicable laws that apply to suits, in which country will these be held, etc.?

- Make sure you understand coverage for services and organizations you work with, e.g., do car rental policies cover damage to the car, damage to other people's property, injuries caused to drivers/passengers? 